\title{
Changes of Air Permeability and Moisture Absorption Capability of the Wood by Organosolv Pretreatment ${ }^{1}$
}

\author{
Chun-Won Kang ${ }^{2} \cdot$ Eun-Suk Jang ${ }^{2} \cdot$ Sangsik Jang ${ }^{3} \cdot$ Ho-Yang Kang $\mathbb{D}^{3, \dagger} \cdot$ \\ Chengyuan $\mathrm{Li}^{4} \cdot$ In-Gyu Choi ${ }^{5}$
}

\begin{abstract}
The air permeability of yellow poplar log cross section before and after organosolv pretreatment was investigated, and the moisture absorption of control and organosolv pretreated rectangular parallelepiped specimens was investigated in this study. It was revealed that the diameters of through pores were enlarged and the number of bigger pore was increased by the organosolv pretreatment. The air permeabilities of the cross sections of yellow poplar log were changed from 1.61 darcy to 23.30 darcy, but their weights were reduced by 5 percent. The equilibrium moisture content of control wood specimen at the exposed relative humidity were $5.9 \%$ at $32 \%, 9.7 \%$ at $58 \%, 14.8 \%$ at $80.5 \%$, $19.7 \%$ at $90 \%, 25.7 \%$ at $95 \%$ and $29.9 \%$ at $100 \%$. The equilibrium moisture content of the specimens pretreated with the parameter of sulfuric acid catalyst of $0.5 \%(\mathrm{w} / \mathrm{w})$ were $19.5 \%$ at $32 \%, 29.3 \%$ at $58 \%$, $39.6 \%$ at $80.5 \%$, $59 \%$ at $90 \%, 111.3 \%$ at $95 \%$ and $111.3 \%$ at $100 \%$, while those pretreated with the parameter of sulfuric acid catalyst of $1.0 \%(\mathrm{w} / \mathrm{w})$ were $17.4 \%$ at $32 \%, 23.9 \%$ at $58 \%, 27.7 \%$ at $80.5 \%$, $40.6 \%$ at $90 \%$, $68.8 \%$ at $95 \%$ and $110.0 \%$ at $100 \%$. The moisture absorption of organosolv pretreated rectangular parallelepiped specimens was higher than that of control specimen.
\end{abstract}

Keywords: air permeability, moisture absorption, organosolv pretreatment

\section{INTRODUCTION}

Interest and research on ethanol extraction production from lignocelluosic material like as wood are increasing and the possibility has been proved (Jang et al., 2016). However, it is difficult to extract the cellulose, which is available as a raw material for bioethanol from the wood because wood is a complex polymeric material consists primarily of cellulose, hemicellulose and lignin, with a minor proportion of extractives and these components combined effectively (Koo et al., 2011; Kang et al., 2012).

${ }^{1}$ Date Received May 4, 2018, Date Accepted October 8, 2018

2 Department of Housing Environmental Design, and Research Institute of Human Ecology, College of Human Ecology, Chonbuk National University, Jeonju 54896, Republic of Korea

${ }^{3}$ Department of Wood Science Technology, College of Agriculture \& Life Science, Chungnam National University, Daejeon 34134, Republic of Korea

${ }^{4}$ Department of Wood Science Technology, Beihua University, China

${ }^{5}$ Program in Environmental Materials Science, College of Agriculture \& Life Science, Seoul National University, Seoul 08826, Republic of Korea

† Corresponding author: Ho-Yang Kang (e-mail: hykang@cnu.ac.kr, ORCID: 0000-0002-0544-0721) 
Several pretreatment technologies were developed in order to improve the extraction process, and various studies are being conducted on pretreatment of woody biomass. Among them, organosolv pretreatment was a pretreating method of effectively removing lignin and xylose in order to effectively acquire glucose by the enzymatic saccharification of pretreated biomass (Mark and Humphrey, 1984; Roland et al., 2010; Jang et al., 2016). When ethanol and sulfuric acid were used as solvent and catalyst, lignin macromolecular were easily dissolved into solvents as forms of low molecular weight fragment even though low reaction temperature, under $160{ }^{\circ} \mathrm{C}$ (Kim et al., 2015). Thus, mitigation of cell wall complexity as well as expansion of pore size could be achieved by elimination of lignin and hemicellulose fraction after organosolv pretreatment (Koo et al., 2011).

In the view of changes of wood properties by organosolv pretreatment, Kang et al. reported (2010) that the organosolv pretreatment improve the air permeability of yellow poplar wood in longitudinal direction and improve the sound absorption coefficient of yellow poplar wood in cross sectional surface on the high frequency range. In addition, in order to use wood as housing acoustic material, the hygroscopicity of wood should be considered.

However, studies on the changes of wood by organosolv pretreatment have been still insufficient. In this study, we investigated the influence of organosolv pretreatment in the air permeability and moisture absorption of yellow poplar specimens by comparing between control and organosolv pretreated specimens.

\section{MATERIALS and METHODS}

\subsection{Specimen preparation}

A 20 years-old yellow-poplar (Liriodendron tulipifera) tree grown in Chodanglim, Jeollanamdo, Korea was harvested and cross-cut. The cross sections with the diameter of $29.9 \mathrm{~mm}$ and the thickness of $10 \mathrm{~mm}$ were prepared. The annual ring widths and weights of them were measured in order to minimize the variation of log cross sections and compared and selected homogeneous log cross sections as specimens. The rectangular parallelepiped specimens with dimension of $20.0 \mathrm{~mm} \times 20.0 \mathrm{~mm} \times 50.0 \mathrm{~mm}$ (radial $\times$ tangential $\times$ longitudinal) were prepared for measuring the moisture absorption of wood based on the method of saturated salt solution.

\subsection{Organosolv pretreatment}

Specimens were impregnated in the solution including ethanol of $50 \%(\mathrm{v} / \mathrm{v})$ and sulfuric acid catalyst of $1 \%(w / w)$ with the reaction temperature of 110 ${ }^{\circ} \mathrm{C}$ for $15 \mathrm{~min}$. Here, the stainless steel batch type reactor was used in case of small log cross section specimen for measuring air permeability, and an autoclave was used for rectangular parallelepiped specimen for measuring moisture absorption. Here, the reactor has maximum capacity of $1,000 \mathrm{ml}$, made by SUS316 stainless steel. Paddle type impeller, heating jacket, thermocouple and pressure gauge were installed and the temperature and stirring speed were adjusted by the controller (Hanwoul Engineering Inc. Gunpo, Gyounggido, Korea).

After the pretreatment, specimens were dried in a desiccator and the weight reduction was measured. 50 $\mathrm{mm}$ long specimens cut from $320 \mathrm{~mm}$ long specimens were oven dried and left in six desiccators for 1 month and their weight were measured and then oven dried. Then, the moisture content and moisture absorption rates were calculated.

\subsection{Determination of carbohydrates for filtrate}

After the organosolv pretreatment, liquid fraction were separated through a $0.45 \mathrm{~lm}$ hydrophilic PTFE 
syringe filter (Advantec Co., Tokyo, Japan), and analyzed by HPLC (HP 1100 series, Agilent Technologies, Santa Clara, CA, USA). The HPLC was equipped with an Aminex HPX-87H column $(300 \mathrm{~mm} \times 7.8 \mathrm{~mm}$ ID $\times$ 9 lm, Bio- Rad Laboratories, Richmond, CA, USA) and was operated at a column temperature of $40{ }^{\circ} \mathrm{C}$ with a mobile phase of $0.01 \mathrm{~N}$ sulfuric acid at a flow rate of $0.5 \mathrm{ml} / \mathrm{min}$. A UV detector at $210 \mathrm{~nm}$ and a refractive index detector were used to quantify products (Kim et al., 2015).

\subsection{Measuring air permeability and pore structure}

The permeability of specimens were measured by Capillary Flow Porometer (Porous Material Incorporated, CFP-1200AEX) (Fig. 2). The air permeability was evaluated using gas flow as a function and the pressure difference. The specimen was put into sample chamber, the chamber was sealed, and then non-reactive nitrogen gas was circulated. The pressure and flow rate of the gas through the specimen were measured. The air permeability of wood specimen was evaluated from the results. The air permeability of wood specimen was calculated according to the equation [1] and [2]. Also, the pore size and pore size distribution were evaluated using liquid and gas flow as a function and the pressure difference as shown in precious research (Jena and Gupta, 2002; Kang et al., 2018).

$$
\begin{gathered}
V=-\left(\frac{k}{\mu}\right) \frac{d p}{d x} \\
F=\frac{k A \Delta P}{\mu L} .
\end{gathered}
$$

where,

$\mathrm{V}=$ Linear flow rate $(\mathrm{m} / \mathrm{s})$

$\mathrm{k}=$ the permeability of a medium $\left(\mathrm{m}^{2}\right)$

$\mu=$ Viscosity of the fluid $\left(\mathrm{N} \cdot \mathrm{s} / \mathrm{m}^{2}\right)$

$\mathrm{p}=$ Pressure $\left(\mathrm{N} / \mathrm{m}^{2}\right)$

$\mathrm{x}=$ Displacement in the direction of flow (m)
F : flow rate in volume $\left(\mathrm{m}^{3} / \mathrm{s}\right)$

A : cross-sectional area of the porous material $\left(\mathrm{m}^{2}\right)$

$\mathrm{L}$ : thickness of the porous material (m)

$\Delta \mathrm{P}$ : Differences in pressure inlet and outlet $\left(\mathrm{N} / \mathrm{m}^{2}\right)$

\subsection{Saturated salt solution experiment}

Five kinds of saturated salt solution and the distilled water of 100 percent were made. Six desiccators in which relative humidity was different were prepared as shown in Table 1. After six $50 \mathrm{~mm}$ long specimens cut from $320 \mathrm{~mm}$ long specimens were oven dried, they left in six desiccators for 1 month, and their weights were measured and then oven dried. Equilibrium moisture content (EMC) of specimen was calculated from equation [3] (Hong et al., 2013).

$$
M=\frac{W_{M}-W_{o d}}{W_{o d}} \times 100
$$

Here, $M=$ moisture content $(\%), W_{M}=$ weight of specimen when moisture content was $M \%(\mathrm{~g}), W_{o d}=$ oven dry weight of specimen (g).

Table 1. Relative humidity and Equilibrium Moisture Contents (EMC) for saturated salt solutions at $20^{\circ} \mathrm{C}$

\begin{tabular}{lcc}
\hline Saturated salt solution & $\mathrm{RH}(\%)$ & EMC \\
\hline \hline $\mathrm{CaCl} 2 \cdot 2 \mathrm{H}_{2} \mathrm{O}$ & 32.0 & 6.0 \\
$\mathrm{NaBr}$ & 58.0 & 10.0 \\
$\left(\mathrm{NH}_{4}\right)_{2} \mathrm{SO} 4$ & 80.5 & 16.0 \\
$\mathrm{ZnSO}_{4} \cdot 7 \mathrm{H}_{2} \mathrm{O}$ & 90.0 & 20.0 \\
$\mathrm{NH}_{2} \mathrm{SO}_{4}$ & 95.0 & 24.0 \\
$\mathrm{H}_{2} \mathrm{O}$ (distilledwater) & 100.0 & 30.0 \\
\hline
\end{tabular}

\section{RESULTS and DISCUSSION}

\subsection{Weight reduction and chemical change after organosolv pretreatment}

Lower temperature $\left(110^{\circ} \mathrm{C}\right)$ was used in this pretreatment compared to general organic solvent 


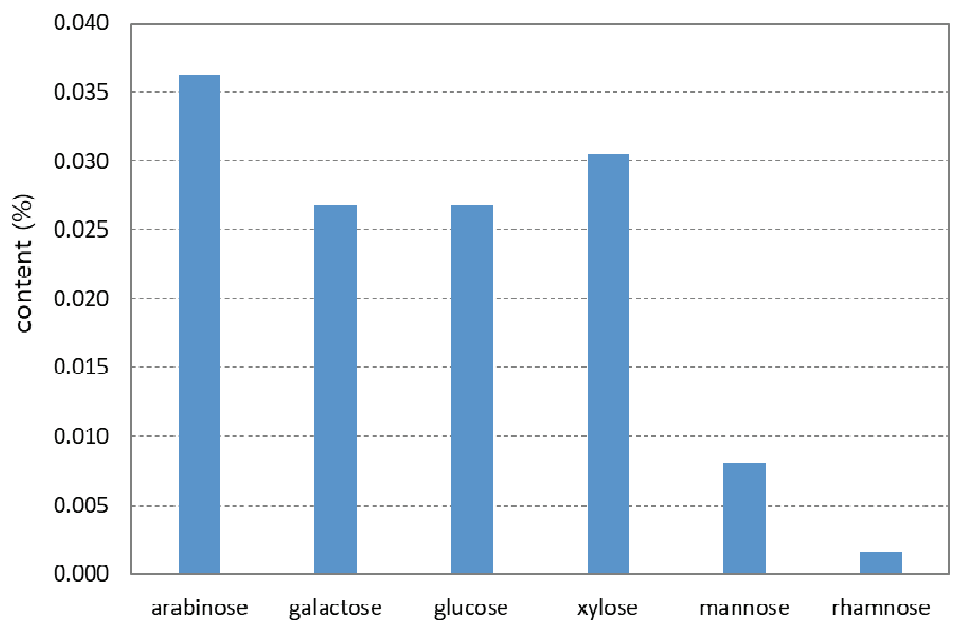

Fig. 1. Carbohydrates content for organosolv pretreated filtrate of yellow poplar.

pretreatment in order to maintain original circle form of specimen during pretreatment (Pan et al., 2008). The result of organic solvent pretreatment showed that weight reduction rate of specimen was $4.81 \%$ when sulfuric acid of $1 \%$ was added and treating time was 15 minutes under temperature of $110{ }^{\circ} \mathrm{C}$.

Determination of carbohydrates for filtrate is shown in Fig. 1. Figure shows that the hemicellulose component such as arabinose and xylose were mainly extracted by the organosolv pretreatment. It is expected that only small part of xylose was extracted by the treatment due to its relatively mild organosolv pretreatment condition. Hemicellulose is typically recognized as a chemical component of biomass which is easily decomposed by thermal and chemical treatment rather than the other components such as cellulose or lignin. When wood is modified by heat, its components degrade and reform. The hemicelluloses are the first to degrade by heat. Degraded hemicelluloses change the hygroscopicity of wood. (Tjeerdsma et al., 1998; Sivonen et al., 2002). Although reaction temperature of $110{ }^{\circ} \mathrm{C}$ is relatively low compared with the typical organosolv pretreatment process, $1 \%$ sulfuric acid sufficiently induced degradation of hemicellulose structure. Additionally, a certain amount of lignin in the specimen can be dissolved in liquid hydrolysate by organic solvent (ethanol) during the reaction. Therefore, the weight reduction of specimen can be comprehended as a result of hemicellulose and lignin decomposition.

\subsection{Permeability change after organosolv pretreatment}

The typical example of permeability of yellow poplar specimens' before and after the organosolv pretreatment were as shown in Fig. 2. Based on the standard of darcy permeability constant, permeability was 1.613 for control specimens and 23.296 for treated specimens, which indicated that the permeability of treated specimens was 14.44 times higher than that of control specimens. This could be accounted for there being more through pores inside treated specimens due to effect of the organosolv pretreatment compared to control specimens. Fig. 3 shows that the pore size distribution as a function of average pore diameter change of control and organosolv pretreated specimen, resulting that the pore diameter was enlarged and 


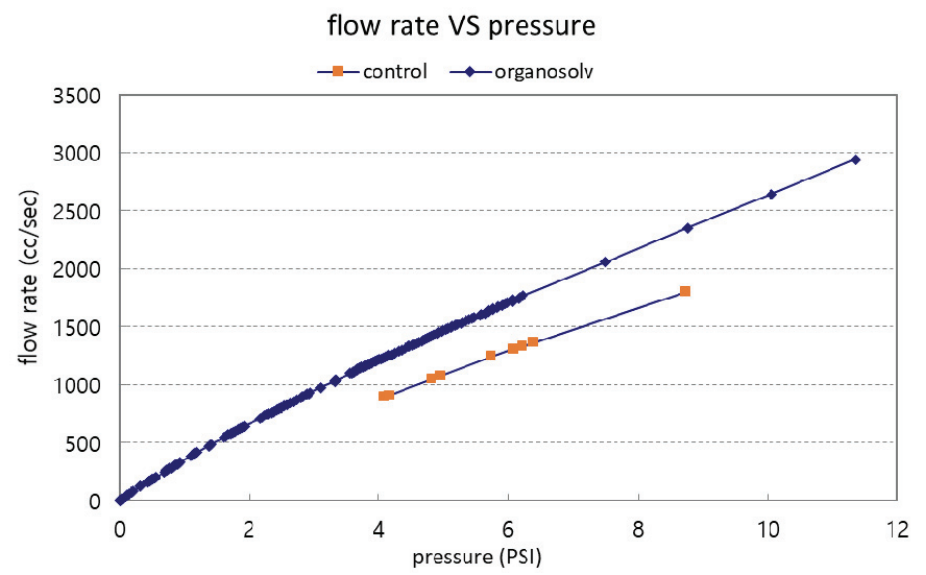

Fig. 2. Air permeability of yellow poplar specimens before organosolv pretreatment.
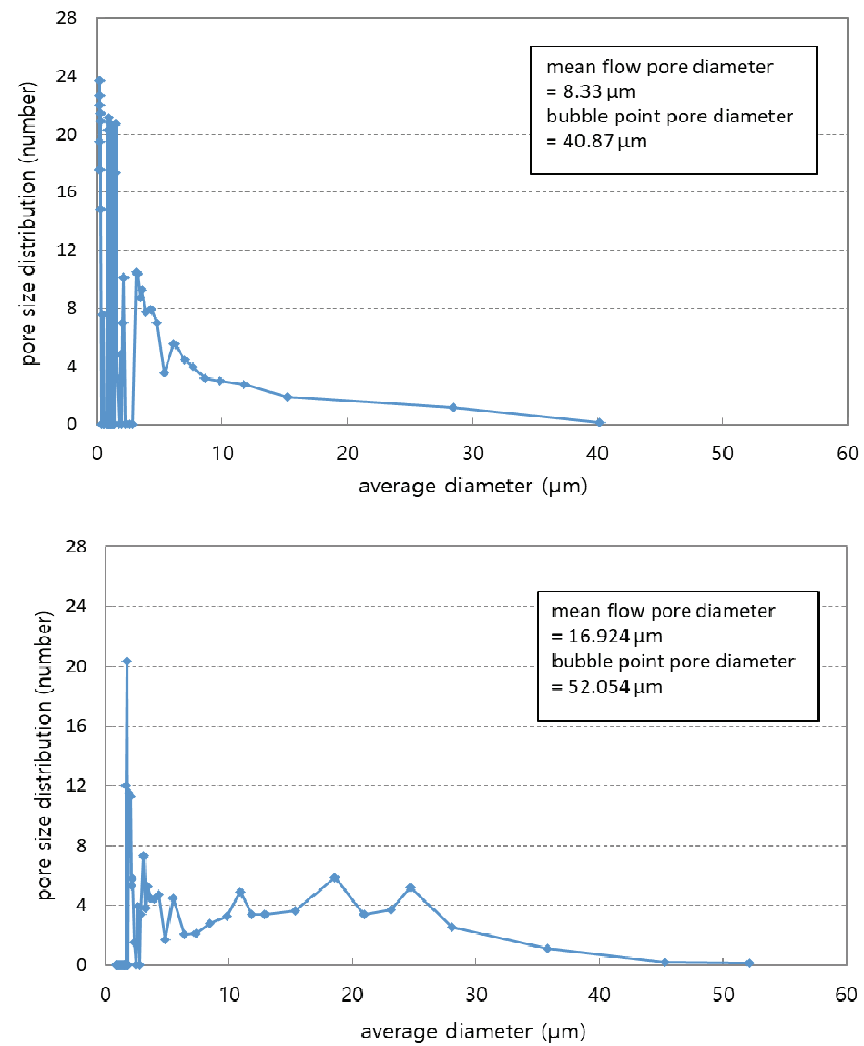

Fig. 3. Pore distribution change of yellow poplar specimens (top, control: bottom, organosolv pretreated). 


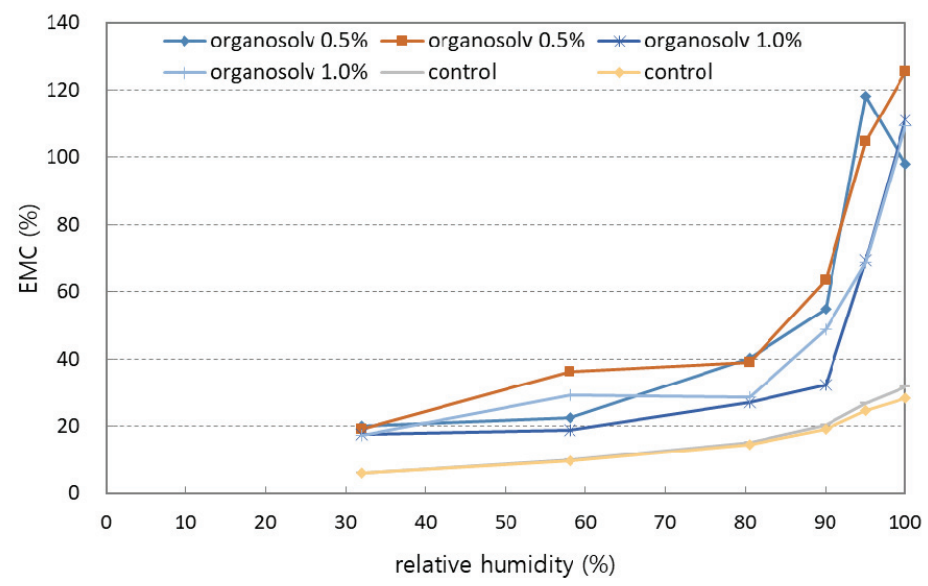

Fig. 4. Relationship between relative humidity and equilibrium moisture content of control and organosolv pretreated wood

the number of bigger pore was increased by the treatment.

As mentioned above, the organosolv pretreatment may induce a significant hemicellulose and lignin degradation in the specimen. In addition, the space in the cell wall structure such as a pore can be enlarged by hemicellulose and lignin removal. Thus, the permeability of cells was improved by expansion of pore size by hemicellulose and lignin degradation after the organosolv pretreatment.

\subsection{Change of moisture absorption rate after organosolv pretreatment}

Equilibrium moisture content and absorption isotherm curve obtained from saturatedsalt solution experiment are as showed in Fig. 4. The equilibrium moisture contents of control wood specimens were 5.9 $\%$ at $32 \% \mathrm{RH}, 9.7 \%$ at $58 \% \mathrm{RH}, 14.8 \%$ at 80.5 $\% \mathrm{RH}, 19.7 \%$ at $90 \% \mathrm{RH}, 25.7 \%$ at $95 \% \mathrm{RH}$ and $29.9 \%$ at $100 \% \mathrm{RH}$. The equilibrium moisture content of the specimens pretreated with the parameter of sulfuric acid catalyst of $0.5 \%(\mathrm{w} / \mathrm{w})$ were $19.5 \%$ at
$32 \% \mathrm{RH}, 29.3 \%$ at $58 \% \mathrm{RH}, 39.6 \%$ at $80.5 \%$ RH, $59 \%$ at $90 \% \mathrm{RH}, 111.3 \%$ at $95 \% \mathrm{RH}$ and $111.3 \%$ at $100 \%$ RH. Those values of the specimens pretreated with the parameter of sulfuric acid catalyst of $1.0 \%(\mathrm{w} / \mathrm{w})$ were $17.4 \%$ at $32 \% \mathrm{RH}, 23.9 \%$ at $58 \% \mathrm{RH}, 27.7 \%$ at $80.5 \% \mathrm{RH}, 40.6 \%$ at 90 $\%$ RH, $68.8 \%$ at $95 \% \mathrm{RH}$ and $110.0 \%$ at $100 \%$ RH. This experiment indicated that the pretreatments increased the equilibrium moisture contents of the specimens and that the equilibrium moisture contents increased with the amount of sulfuric acid catalyst. Equilibrium moisture content was much higher for treated specimens than for control specimens, which could be increased moisture absorption rate of treated specimens due to pore structure change because of the organosolv treatment. Ljungdahl and Berglund (2007) referred that the wood components degradation leads to oxidized chemical groups, which increase the hygroscopicity. We surmised that the increased moisture absorption was caused by the wood composition degradations and pore structure changes by the organosolv treatment. 


\section{CONCLUSION}

The permeability and moisture absorption of yellow poplar log cross section after the organosolv pretreatment was measured to investigate change of the permeability and moisture absorption in this study. The results of this study were as followings,

1. The permeability of organic solvent pretreated specimens was significantly increased.

2. The weight of organic solvent pretreated specimens was reduced by 5 percent.

3. The moisture absorption of organic solvent pretreated specimens was significantly increased due to pore structure change.

\section{ACKNOWLEDGMENT}

This research was supported by Basic Science Research Program through the National Research Foundation of Korea (NRF) funded by the Ministry of Science and ICT (NRF-2017R1A2B4012538).

\section{REFERENCES}

Hong, S-H., Kim, C-H, Lim, H-M., Kang, H-Y. 2013. Measuring PEG retentions and EMCs of PEG impregnated softwood specimens after heat treatment. Journal of the Korean Wood Science and Technology 41(3): 173-180.

Jang, S-K., Kim, H-Y., Jeong, H-S., Kim, J-Y., Yeo, H-M., Choi, I-G. 2016. Effect of ethanol organosolv pretreatment factors on enzymatic digestibility and ethanol organosolv lignin structure from Liriodendron tulipifera in specific combined severity factors. Renewable Energy 87: 599-606.

Jena, A., Gupta, K. 2002. Characterization of pore structure of filtration media. Fluid/particle Separation Journal 14(3): 227-241.

Kang, C-W., Kang, W., Chung, W-Y., Matsumura, J.,
Kazuyuki, O. 2008. Changes In Anatomical Features, Air Permeability And Sound Absorption Capability Of Wood By Delignification Treatment. Journal of the faculty of agriculture kyushu university 53(2): 479-483.

Kang, C-W., Kim, G.C., Park, H-J., Lee, N-H., Kang, W., Matsumura, J. 2010. Changes in permeability and sound absorption capability of yellow poplar wood by steam explosion treatment. Journal of the faculty of agriculture kyushu university 55(2): 327-332.

Koo, B-W., Kim, H-Y., Park, N., Lee, S-M., Yeo, H-M., Choi, I-G. 2011. Organosolv pretreatment of Liriodendron tulipifera and simultaneous saccharification and fermentation for bioethanol production. Biomass and Bioenergy 35(5): 18331840.

Kang, C-W., Li, C., Jang, E-S., Jang, S-S., Kang, H-Y. 2018. Changes in Sound Absorption Capability and Air Permeability of Malas (Homalium foetidum) Specimens after High Temperature Heat Treatment. Journal of the Korean Wood Science and Technology 46(2): 149-154.

Kang, C-W., Choi, I-G., Gwak, K-S., Yeo, H-M., Lee, N-H., Kang, H-Y. 2012. Changes of Sound Absorption Capability of Wood by Organosolv Pretreatment. Journal of the Korean Wood Science and Technology 40(4): 237-243.

Kim, H-Y., Jeong, H-S., Lee, S-Y., Choi, J-W., Choi, I.G. 2015. Pd-catalyst assisted organosolv pretreatment to isolate ethanol organosolv lignin retaining compatible characteristics for producing phenolic monomer. Fuel 153: 40-47.

Ljungdahl, J. Berglund, L.A. 2007. Transverse mechanical behaviour and moisture absorption of water logged archaeological wood from the Vasa ship. Holzforschung, 61: 279-284.

Mark T. Holtzapple and Arthur E. Humphrey. 1984. The effect of organosolv pretreatment on the 
enzymatic hydrolysis of poplar. Biotechnology and Bioengineering 26(7): 670-676.

Roland E.H., Nicolas B., Poulomi S., Arthur R. 2010. Effects of process severity on the chemical structure of Miscanthus ethanol organosolv lignin. Polymer Degradation and Stability 95(6): 997-1003.

Sivonen, H., Maunu, S., Sundholm, F., Jamsa, S., Viitaniemi, P. 2002 Magnetic Resonance Studies of Thermally Modified Wood. Holzforschung, 56: 648-654.
Pan, X., Xie, D., Richard, W.Y., Jack, N.S. 2008. The bioconversion of mountain pine beetle-killed lodgepole pine to fuel ethanol using the organosolv process. Biotechnology and Bioengineering 101(1): 39-48.

Tjeerdsma, B., Boonstra, M., Pizzi, A., Tekely, P., Militz, H. 1998 Characterisation of thermally modified wood: molecular reasons for wood performance improvement. Holz Roh-Werkst 56: 149-153. 